\title{
АДИПОНЕКТИН - КАК ФАКТОР РИСКА РАЗВИТИЯ МЕТАБОЛИЧЕСКИХ НАРУШЕНИЙ У БОЛЬНЫХ С ДИАБЕТИЧЕСКОЙ ПОЛИНЕЙРОПАТИЕЙ
}

\author{
${ }^{1}$ Ширалиева Р.К., ${ }^{3}$ Гейдарова Н.Г., ${ }^{2}$ Ахмедова 3.Г.* \\ Азербайджанский Государственный Институт Усовершенствования врачей им. А.Алиева,

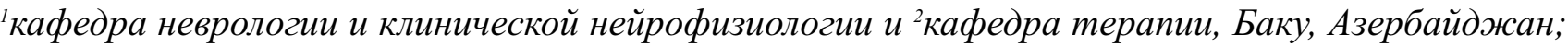

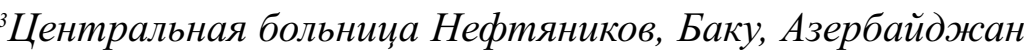

Цель исследования заключалась в оценке уровня адипонектина в сыворотке крови у больных с диабетической полинейропатией. В исследовании приняли участие 86 больных диабетической полинейропатией (ДПН), из которых мужчины составили 64,0\%, женщины - 36,0\%. У обследованных пациентов с ДПН показатель HOMA (Homeostasis model assessment) в среднем превышал нормативные показатели в 2,2 раза ( $<0,01)$. Существенных различий в показателях между мужчинами и женщинами выявлено не было. Лишь содержание инсулина в крови и величина HOMA-IR у мужчин были выше на $52,2 \%(\mathrm{p}<0,05)$ и на $36,6 \%(\mathrm{p}<0,05)$ соответственно. Уровень адипонектина как у мужчин, так и женщин были достоверно ниже референсных величин, соответственно в 2,4 раза $(\mathrm{p}<0,01)$ и в 1,3 раза (p<0,05). Выявлено что адипонектин выше у женщин в 1,5 раза $(\mathrm{p}<0,05)$. Содержание адипонектина в крови у женщин коррелировало средней прямой связью с гликогемоглобином (r=+0.377), а у мужчин выявлена наиболее тесная связь адипонектина с показателем инсулинорезистентности $(\mathrm{r}=+0.421)$. Установлена целесообразность использования результатов уровня адипонектина в патогенезе ДПН. Уровень адипонектина является важным критерием для определения степени тяжести, контроля за лечением, а также прогноза заболевания.

Ключевые слова: диабетическая полинейропатия, СД 2 типа, инсулинорезистентность, адипонектин, корреляция.

\section{ростом распространенности диабета, это заболевание стало основной причи- ной патологических проявлений и} смертности. Диабетическая полинейропатия (ДПН) является одним из наиболее распространенных и сложных хронических осложнений сахарного диабета 2-го типа, создающих огромную экономическую проблему [1-3].

Сахарный диабет является важным независимым фактором риска полинейропатии, но высокий риск полинейропатии у пациентов с диабетом не полностью объясняется традиционными факторами риска.

При сахарном диабете нарушение метаболизма приводит к сосудистым нарушениям, которые, в свою очередь, являются причиной нарушения кровоснабжения нервных волокон-диабетической нейропатии [1,3]. Причем, чем выше стаж сахарного диабета и хуже гликемический контроль, тем хуже будет состояние нервных волокон и больше проявления неврологических симптомов, дисфункции периферических нервов.

Среднее время развития ДПН около 9 лет. Диагностика ДПН основывается на выявлении типичной симптоматики: боль, жжение, онемение, парестезии и позитивной нейропатической симптоматики: снижение чувствительности болевой, температурной и вибрационной, сни- жение или отсутствие сухожильных рефлексов на ногах (в первую очередь ахилловых), которая клинически проявляется сухостью кожи, покраснением, повышением температуры. Для постановки окончательного диагноза необходимо провести инструментальное исследование, а именно электромиографию (ЭМГ).

Исследование уровня адипонектина, по мнению ряда авторов, так же может быть информативным для диагностики нейропатии [4,5]. Адипонектин, представляет собой адипокин, который имеет ряд преимуществ, связывающих его с инсулином, обладает противовоспалительным и антиатеросклеротическим эффектами [5]. Этот пептид в основном изучался в некоторых заболеваниях, таких как метаболический синдром, ожирение и сахарный диабет. Он играет важную роль в повышении чувствительности к инсулину, стимулируя фосфорилирование АМФ-активированной протеинкиназы в целевых для инсулина органах, таких как скелетные мышцы и печень [5].

Адипонектин, самый распространенный адипоцитокин. Известно, что адипонектин снижается при ожирении, резистентности к инсулину, при диабете типа 2, макрососудистых осложнениях и болезни коронарных артерий [5]. Кроме того, адипонектин улучшает чувствительность к инсулину и снижает гипергликемию. Недоста-

*e-mail: endo.ziba@gmail.com 
ток адипонектина может повлиять на развитие или прогрессирование диабетических микрососудистых осложнений. Однако взаимосвязь между микрососудистыми осложнениями и уровнем адипонектина в сыворотке, как отмечено выше, противоречива. Китайские ученые в своих исследованиях отметили низкий уровень адипонектина у больных с диабетической нейропатией по сравнения с лицами без неё [6]. Matsuda et al. проанализировали взаимосвязь адипонектина с диабетической нейропатией и не выявили ассоциации между ними [7]. Так же в исследовании Kato et al. показано отсутствие корреляции сывороточного адипонектина с нейропатией [8]. В ряде исследований, отмечено, что адипонектин способствует повышенному риску сосудистых осложнений и имеет тенденцию к снижению при гипергликемии и инсулинорезистентности [3,9].

Причины несоответствия результатов между исследованиями не ясны. Одним из возможных объяснений является то, что диагноз невропатии основывался на разных критериях. В вышеупомянутых исследованиях диагноз невропатии был установлен с помощью лишь одного метода исследования-определения скорости проводимости нерва посредством электрической стимуляции или физического обследования. Противоречия по этому вопросу могут быть в результате различий в популяциях, исследования в соответствии с различными диагностическими критериями. Этнические различия также могли повлиять на взаимосвязь между диабетическими осложнениями и уровнем адипонектина в сыворотке.

Целью настоящего исследования было оценить уровень адипонектина в сыворотке крови у больных с диабетической полинейропатией.

Материалы и методы. В исследовании приняли участие 86 больных с ДПН, из которых мужчин было 55 (64,0\%), женщин- 31 (36,0\%). Пациенты находились на стационарном лечении в эндокринологическом отделении РКБ им. акад. Мир-Касимова.

Критериями исключения составили пациенты с почечной, печеночной и сердечной недостаточностью, тяжелой гипертензией, с инсультом, острой или хронической инфекцией, аутоиммунными заболеваниями, СД 1 типа, беременные и т.д.

У всех больных был собран анамнез, выявлены жалобы, осмотрен внешний вид нижних конечностей. В процессе исследования проведено общее клиническое обследование, включающее измерение АД по Короткову, определение пульса. Определены концентрация глюкозы натощак, уровень гликированного гемоглобина (HbA1c) в крови, который определяли на биохимическом анализаторе, количество инсулина в крови методом ИФА.

Для определения инсулинорезистентности рассчитывали индекс HOMA-IR в малой модели гомеостаза (Homeostasis model assessment) по формуле:

\section{HOMA-IR $=\frac{\text { (инсулин натощак (мкЕД/мл)х глюкоза плазмы натощак (ммоль/л) }}{22,5}$}

За норму принимали значение не более 2,77 (Matthews D.R. et al., 1985).

Определение количества адипонектина в сыворотке крови проводили методом ИФА, с помощью тест-набора Mediagnost E09 Adiponectin - ELISA (Германия).

При выполнении данной работы учитывалась Хельсинская декларация Всемирной медицинской ассоциации «Рекомендации для врачей, занимающихся биомедицинскими исследованиями с участием людей» [World Med. Associat. Declar., 2013]. Все пациенты были ознакомлены с целью исследования и дали письменное согласие.
Статистическую обработку полученных результатов и построение диаграмм проводили, применяя программы Statistica 10.0 и MicrosoftExcel 2010. Рассчитывали среднее арифметическое значение (М), стандартную ошибку (m). Достоверность различий определяли по t-критерию Стьюдента. О корреляционной связи между показателями судили по коэффициенту корреляции Пирсона. Уровень значимости при статистическом анализе принимали при $\mathrm{p} \leq 0,05$.

Результаты и их обсуждение. В табл. 1 представлена общая характеристика пациентов с ДПН. 
Характеристика пациентов с ДПН

\begin{tabular}{|l|l|}
\hline \multicolumn{1}{|c|}{ Показатель, ед. измерен. } & \multicolumn{1}{c|}{ Больные с ДПН $(\mathrm{n}=86)$} \\
\hline Возраст, лет & $51,79 \pm 7,94(18-67)$ \\
\hline Длительность СД 2 типа, лет & $8,58 \pm 2,53(1-20)$ \\
\hline НОМА & $6,01 \pm 3,98(0,1-29,33)$ \\
\hline Глюкоза в крови, ммоль/л & $10,01 \pm 2,99(4,3-17)$ \\
\hline Инсулин, мкЕД/мл & $27,98 \pm 17,49(1,2-101)$ \\
\hline НbА1с, \% & $12,78 \pm 1,13(10-14,4)$ \\
\hline
\end{tabular}

Исследования показали, что у обследованных пациентов с ДПН показатель НОМА в среднем превышал нормативные показатели в 2,2 раза $(p<0,01)$, при этом со значением
НОМА не более 2,77 встречались 22,1\% пациентов.

В табл. 2 представлена общая характеристика мужчин и женщин с ДПН.

\section{Клинические показатели мужчин и женщин с ДПН}

Таблица 2

\begin{tabular}{|l|l|l|}
\hline \multicolumn{1}{|c|}{ Показатели } & \multicolumn{1}{|c|}{ Мужчины $(\mathrm{n}=55)$} & \multicolumn{1}{c|}{ Женщины $(\mathrm{n}=31)$} \\
\hline Средний возраст, лет & $53,85 \pm 6,56(31-66)$ & $48,91 \pm 10,11(18-67)$ \\
\hline Рост, см & $172,39 \pm 4,97(152-180)$ & $163,9 \pm 6,10(152-173)$ \\
\hline Вес, кг & $84,57 \pm 6,63(59-97)$ & $75,8 \pm 12,4(48-98)$ \\
\hline ОТ, см & $106,750 \pm 6,0(90-115)$ & $105,0 \pm 8,0(83-128)$ \\
\hline ИМТ, кг/м ${ }^{2}$ & $29,8 \pm 3,24(20-37)$ & $28,68 \pm 3,66(18,75-37)$ \\
\hline Длительность СД 2т, лет & $8,82 \pm 2,69(1-20)$ & $8,22 \pm 2,22(3-17)$ \\
\hline САД, мм рт.ст. & $155,14 \pm 15,91(120-220)$ & $147,5 \pm 16,67(100-200)$ \\
\hline ДАД, мм рт.ст. & $87,37 \pm 9,47(60-120)$ & $87,31 \pm 10,28(60-120)$ \\
\hline Пульс, уд/мин & $84,32 \pm 4,46(75-108)$ & $83,62 \pm 5,79(70-110)$ \\
\hline Глюкоза, ммоль/л & $10,51 \pm 3,15(4,8-17)$ & $9,27 \pm 2,64(4,3-15)$ \\
\hline Инсулин, мкЕД/мл & $23,58 \pm 14,81(2,7-101)^{*}$ & $15,20 \pm 7,61(1,2-39)$ \\
\hline НОМА-ІR & $6,83 \pm 4,89(0,78-29,33)^{*}$ & $5,0 \pm 2,48(1,01-15,04)$ \\
\hline НьА1с, \% & $12,57 \pm 1,35(10-14,4)$ & $13,21 \pm 0,73(12-14)$ \\
\hline
\end{tabular}

Примеч: * - статистическая достоверность различий между показателями $(\mathrm{p}<0,05)$

Как видно из табл. 2, существенных различий в показателях между мужчинами и женщинами выявлено не было. Лишь содержание инсулина в крови и величина HOMA-IR у мужчин были выше на $52,2 \%(p<0,05)$ и на $36,6 \%(p<0,05)$ соответственно.

При определении содержания адипонектина в крови выявлено его колебание у мужчин в интервале $0,1-9,5 \mu \mathrm{g} / \mathrm{ml}$ (референсные значения - 2,7-10,9 $\mu \mathrm{g} / \mathrm{ml})$, у женщин - 0,1-14,0 $\mu \mathrm{g} / \mathrm{ml}$ (референсные значения - 5,6-14,8 $\mu \mathrm{g} / \mathrm{ml}$ ) (рис.1).

Уровень адипонектина как у мужчин, так и женщин были достоверно ниже, чем референсные величины, соответственно в 2,4 раза $(\mathrm{p}<0,01)$ и в 1,3 раза $(\mathrm{p}<0,05)$. При сравнении содержания адипонектина в сыворотке крови между мужчинами и женщинами выявлено что у женщин в 1,5 раза $(\mathrm{p}<0,05)$ адипонектин выше, чем у мужчин.

Проведенный анализ показал, что концентрация адипонектина в крови в пределах референсных значений у мужчин (2,7-10,9 $\mu \mathrm{g} / \mathrm{ml})$ отмечалась у 32 пациентов, что составило 58,2\%, у 23 (41,8\%) пациентов значения адипонектина были ниже, соответственно у $10(32,3 \%)$ женщин уровень адипонектина находился в диапазоне референсных значений, у $21(67,7 \%)$ ниже референсных значений. 


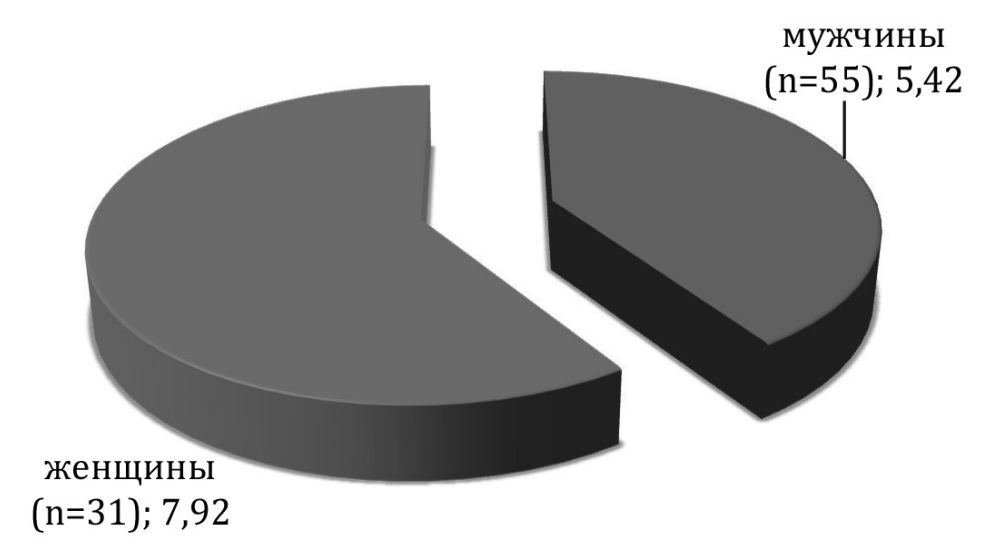

\section{Рис.1. Средний уровень сывороточного адипонектина $(\mu \mathrm{g} / \mathrm{ml})$ у обследованных пациентов с ДПН}

Полученные результаты показали, что у пациентов с высоким ИМТ (более 25 кг $/ \mathrm{M}^{2}$ ) величина адипонектина в среднем у мужчин составила $4,66 \pm 3,08 \mu \mathrm{g} / \mathrm{ml}$, у женщин - 11,2 $\pm 2,2 \mu \mathrm{g} / \mathrm{ml}$. У больных с высоким показателем инсулинорезистентности (HOMA-IR >2,7) средний уровень ади- понектина составил у мужчин $6,13 \pm 4,33 \mu \mathrm{g} / \mathrm{ml}, \mathrm{y}$ женщин - 7,45 $\pm 5,14 \mu \mathrm{g} / \mathrm{ml}$.

Проведенный корреляционный анализ между адипонектином и диагностическими показателями, характерные для СД 2 т, выявил различные связи (табл. 3).

Таблица 3

Коэффициент корреляции (r) между уровнем адипонектина и другими параметрами

\begin{tabular}{|l|c|c|}
\hline Показатель & Мужчины $(\mathrm{n}=55)$ & Женщины $(\mathrm{n}=31)$ \\
\hline Длительность СД 2 т<5 лет & $+0,288$ & $-0,601$ \\
\hline Длительность СД 2 т 5-10 лет & $+0,010$ & $-0,153$ \\
\hline Глюкоза натощак & $-0,018$ & $+0,313$ \\
\hline Инсулин & $-0,043$ & $-0,340 *$ \\
\hline НОМА & $+0,421$ & $-0,138$ \\
\hline НbА1с & $-0,022$ & $+0,377$ \\
\hline ИМТ $>25$ кг/м & $+0,029$ & $-0,343$ \\
\hline
\end{tabular}

Примечание: * - статистическое достоверное различие между показателями

У пациентов с ДПН отмечается разнонаправленная корреляция с длительностью СД2т 5 и менее лет, у мужчин она слабая и положительная, а у женщин - средняя и отрицательная. У мужчин и женщин при длительности СД 2т 5-10 лет корреляционная связь с адипонектином ослабляется соответственно в 28,8 раз $(\mathrm{p}<0,001)$ и в 3,9 раза $(\mathrm{p}<0,001)$.

Уровень глюкозы в крови у мужчин практически не коррелирует с уровнем адипонектина, о чем свидетельствует слабая обратная связь между ними, тогда как у женщин эта связь отрицательная и средней степени. Количество инсулина в крови коррелирует с концентрацией ади- понектина и у мужчин, и у женщин отрицательной связью, но у женщин она более выражена $(\mathrm{p}<0,001)$, по сравнению с мужчинами. У мужчин адипонектин коррелирует с показателем инсулинорезистентности отрицательной умеренной связью, тогда как у женщин такая связь не отмечается. В тоже время у женщин выявляется положительная средняя корреляция адипонектина c HbAlc, тогда как у мужчин аналогичная корреляция отрицательная и очень слабая. С ИМТ уровень адипонектинау мужчин коррелировал очень слабой отрицательной связью, у женщин между этими показателями отмечалась средняя отрицательная связь. 
Таким образом, у пациентов с ДПН уровень сывороточного адипонектина снижен, причем, у женщин в сравнении с мужчинами, он статистически больше снижен в 1,5 раза $(\mathrm{p}<0,05)$. Содержание адипонектина в крови у женщин коррелировало средней положительной связью с гликогемоглобином $(\mathrm{r}=+0,377)$, а у мужчин выявлена наиболее тесная связь адипонектина с показателем инсулинорезистентности $(\mathrm{r}=+0,421)$.

Наши данные показали, что гендерные различия концентрации адипонектина между женщинами и мужчинами, возможно, из-за различных видов ожирения (абдоминального или висцерального) у разных полов. Было установлено, что показатель НОМО-РИ также является важным фактором, взаимодействия с уровнем адипонектина, так как от его уровня зависит резистентность к инсулину. Более длительная продолжительность заболевания сахарным диабетом пациентов с ДПН (5-10 лет), по сравнению с пациентами, длительность заболевания которых составила до 5 лет, показала, что ДПН представляет собой длительный процесс хронического повреждения.

В соответствии с нашими результатами, у пациентов СД 2 типа, уровень адипонектина в сыворотке отрицательно коррелировал с количеством инсулина в крови, причем, как у мужчин, так и женщин.

По данным литературы, адипонектин не только уменьшает ИР. Он также стимулирует секрецию инсулина, подавляет глюконеогенез в печени, способствует окислению жирных кислот и усвоению глюкозы в скелетных мышцах, регулирует экспрессию рецептора инсулина $[11,12]$. Следовательно пониженная секреция адипонектина означает риск развития СД2 типа [11]. По данным С.А. Савельевой и соавт. [13], снижение секреции адипонектина отмечается у $89 \%$ больных СД2 типа. И.Л. Никитина и соавт.[14] указывают на наличие сильной обратной корреляции содержания адипонектина в сыворотке крови с уровнем гликированного гемоглобина.
Наши результаты показали слабую обратную корреляцию между этими показателями у мужчин $(\mathrm{r}=-0,022)$ и среднюю прямую корреляционную связь у женщин $(\mathrm{r}=+0,377)$ при ДПН

По данным ряда авторов очевидно, что риск развития СД2 типа не зависит от того, уровень какой изоформы адипонектина в плазме снижен [15]. На этапе нарушения толерантности к глюкозе наряду с дислипидемией, гиперинсулинемией уже наблюдается гипоадипонектинемия [5]. Установлены гендерные различия в снижении уровня адипонектина: у женщин нарушения его секреции более выражены и начинаются уже при нарушении толерантности к глюкозе, а у мужчин проявляются только при СД2 типа [5]. Причины таких половых различий неясны. В последнее время снижение уровня адипонектина в крови при СД 2т стали объяснять наличием ожирения [16,17]. У больных СД 1-го типа без ожирения при ИР также отмечалось снижение уровня адипонектина [18].

По нашим данным, из всех клинических параметров, больше всего, адипонектин и ИМТ были существенными факторами в отношении развития ДПН. По всей вероятности, немаловажная роль в механизме развития ДПН принадлежит окислительному стрессу. Для окончательного решения этой гипотезы, необходимы дальнейшие научные подтверждения.

На основании полученных результатов исследования, можно констатировать, что сывороточный адипонектин является одним из существенных факторов, влияющих на развитие ДПН, что указывает на то, что низкий уровень адипонектина способствовал развитию ДПН. Наши результаты, представленные в этом исследовании, позволяют нам дополнительно определить целесообразность использования результатов уровня адипонектина в патогенезе ДПН. На наш взгляд уровень адипонектина является важным критерием для определения степени тяжести, контроля за лечением, а так же прогноза заболевания. 


\section{ЛИТЕРАТУРА - REFERENCES - ӘDӘВIYYYAT}

1. Головачева В.А., Зиновьева О.Е. Диабетическая полинейропатия: от науки к практике. Медицинский совет. 2015; 7: 18-22.

2. Котов С.В., Калинин А.П., Рудакова И.Г. Диабетическая нейропатия. Москва: МИА, 2011: 438.

3. Ybarra-Munoz J., Jurado-Campos J., Garcia-Gil M. et al. Cardiovascular disease predicts diabetic peripheral polyneuropathy in subjects with type 2 diabetes: A 10-year Prospective Study. European Journal of Cardiovascular Nursing, 2016; 15 (4): 248-254.

4. Ассоциация между уровнями адипоцитокина в сыворотке и микроангиопатиями у пациентов с сахарным диабетом 2-го типа J Diabetes Investig, 2014; 5(3)

5. Терещенко И.В., Каменских Я.А., Суслина А.А. Адипонектин в норме и патологии. Терапевтический архив. 2016;12:126-132 doi: 10.17116/terarkh20168812126132

6. Li L., Chen J., Wang J., Cai D. Prevalence and risk factors of diabetic peripheral neuropathy in type 2 diabetes mellitus patients with overweight/obese in Guangdong province, China. Primary Care Diabetes, 2015; 9(3): p.191-195.

7. Мацуда М., Кавасаки Ф., Иноуэ Х. и др. Возможный вклад адипоцитокинов в диабетическую невропатию. Диабет Res Clin практике.2004; 66: S121-S123

8. Kato K, Osawa H, Ochi М. идр. Уровень адипонектина в сыворотке и высокомолекулярном уровне адипонектина коррелируют с тяжестью диабетической ретинопатии и нефропатии. Clin. Endocrinol., 2008;68: p.442-449

9. Chan-Hee Jung, Bo-Yeon Kim, Ji-Oh Mok, Sung-Koo Kang, Chul-Hee Kim Association between serum adipocytokine levels and microangiopathies in patients with type 2 diabetes mellitus. J Diabetes Investig. 2014;5(3): 333-339.

10. World Medical Association Declaration of Helsinki Ethical Principles for Medical Research Involving Human Subjects // JAMA, 2013, vol.310, No 20, p. 2191-2194.

11. Lindberg S, Jensen JS, Pedersen SH, Galatius S, Frystyk J, Flyvbjerg A, Bjerre M, Mogelvang R. Lindberg Low adiponectin levels and increased risk of type 2 diabetes in patients with myocardial infarction. Diabetes Care. 2014;37(11):3003-3008. doi:10.2337/dc14-093

12. Ma H, Cui F, Dong JJ, You GP, Yang XJ, Lu HD, Huang YL. Therapeutic effects of globular adiponectin in diabetic rats with nonalcoholic fatty liver disease. World J Gastroenterol. 2014; 20(40):14950-14957. doi:10.3748/wjg.v20.i40.14950

13. Савельева С.А., Крячкова А.А., Курумова К.О, Шамхалова М.Ш., Кутырина И.М., Шестакова М.В. Ожирение - фактор риска поражения почек у больных сахарным диабетом 2-го типа. Сахарный диабет. 2010;2:45-50.

14. Никитина И.Л., Тодиева А.М., Каронова Т.Л., Гринева Е.Н. Взаимосвязь уровня витамина D, содержания адипоцитокинов и метаболических нарушений у детей с ожирением. Бюллетень Федерального центра сердца, крови и эндокринологии им. В.А. Алмазова. 2013 Июнь: 37-46.

15. Li Y, Wu QH, Jiao ML, Fan XH, Hu Q, Hao YH, Liu RH, Zhang W, Cui Y., Han LY. Gene-environment interaction between adiponectin gene polymorphisms and environmental factors on the risk of diabetic retinopathy. J Diabet Invest. 2015;6(1):56-66. doi:10.1111/jdi.12249

16. Al-Hamodi Z, Al-Habori M, Al-Meeri A, Saif-Ali R. Assosiation of adipokines, leptin/adiponectin ratio and $\mathrm{C}$ reactive protein with obesity and tipe 2 diabetes mellitus. Diabet Metabol Syndrome. 2014;6(1):99. doi:10.1186/17585996-6-9

17. Титов В.Н. Биологическая функция трофологии (питания) и патогенез метаболического синдрома - физиологического переедания. филогенетическая теория общей патологии, лептин и адипонектин. Кардиологический вестник. 2014;1:79-93.

18. Pereira RI, Snell-Bergeon JK, Erickson C, Shauer IE, Bergman BC, Rewers M, Maahs DM. Adiponectin dysregulation and insulin resistance in type 1 diabetes. J Clin Endocrinol Metabol. 2012;97(4):E642-647. doi:10.1210/jc.2011-2542 


\title{
XÜLASə
}

\section{ADIPONEKTIN - DİABETIK POLINEYROPATIYALI XəSTOLӘRDӘ METABOLIK XəSTəLİKLəRIN İNKIŞAFI ÜÇÜN RİSK AMILII KIMI}

\author{
${ }^{1}$ Şirəliyeva R.K., ${ }^{3}$ Heydərova N.H., ${ }^{2}$ Ohmədova Z.Q. \\ O.Oliyev ad. Azərbaycan Dövlat Hakimlari Təkmillaşdirmə Institutu, 'nevrologiya və \\ klinik neyrofiziologiya kafedrası vo 'terapiya kafedrası, Bakl, Azərbaycan; \\ ${ }^{3}$ Markazi Neftçilar Xastaxanası, Bakl, Azarbaycan
}

Tədqiqatın məqsədi diabetik polineyropatiyalı (DPN) xəstələrin qan serumunda adiponektin səviyyəsinin qiymətləndirilməsidir. Tədqiqata DPN 86 xəstə cəlb olunub, kişilər $64,0 \%$, qadınlar isə 36,0\% təşkil edib. DNP ilə müayinə olunmuş xəstələrdə HOMA (Homeostasis model assessment) indeksi normativ göstəricilərdən 2,2 dəfə üstün olmuşdur $(\mathrm{p}<0,01)$. Qadın və kişilər arasında göstəricilərdə əhəmiyyətli fərqlər alınmamışdır. Təkcə insulinin qanda miqdarı və HOMA-İR kişilərdə 52,2\% $(\mathrm{p}<0,05)$ və qadınlarda $36,6 \%(\mathrm{p}<0,05)$ yüksək olmuşdur. Adiponektinin səviyyəsi kişi və qadınlarda referens ölçülərdən müvafiq şəkildə 2,4 ( $p<0,01)$ və 1,3 dəfə $(p<0,05)$ statistik dürüst aşağ olmuşdur. Qadınlarda adiponektinin miqdarının 1,5 dəfə $(\mathrm{p}<0,05)$ artması müəyyən edilmişdir. Qadınlarda adiponektinin qanda miqdarının qlikohemoqlobinlə orta və düzünə əlaqəsi $(r=+0,377)$, kişilərdə isə adiponektinin insulinrezistentlik göstəricisi ilə daha six $(\mathrm{r}=+0,421)$ korrelyasiyası müəyyən edilmişdir. DPN patogenezində adiponektin səviyyəsinin nəticələrindən istifadə etməyin məqsədəuyğunluğu müəyyən olunmuşdur. Adiponektinin səviyyəsi DNP ağırlıq dərəcəsini, müalicəsinə nəzarəti, həmçinin xəstəliyin proqnozunu müəyyənləşdirmək üçün vacib meyardır. Açar sözlər: diabetik polinevropatiya, şəkərli diabet 2 tip, insulinrezistentlik, adiponektin, korrelyasiya.

\section{SUMMARY}

\section{ADIPONECTIN AS A RISK FACTOR FOR THE DEVELOPMENT OF METABOLIC DISORDERS IN PATIENTS WITH DIABETIC POLYNEUROPATHY}

\author{
${ }^{1}$ Shiraliyeva R.K., ${ }^{3}$ Heydarova N.H., ${ }^{2}$ Ahmadova Z.G. \\ Azerbaijan State Advanced Training Institute for Doctors named after A.Aliyev, ${ }^{1}$ Department of \\ Neurology and Clinical Neurophysiology and '2Department of Therapy, Baku, Azerbaijan; \\ ${ }^{3}$ Central Hospital of Oil Workers, Baku, Azerbaijan
}

The aim of the study was to assess the level of adiponectin in the blood serum in patients with diabetic polyneuropathy. The study involved 86 patients with diabetic polyneuropathy (DPN), of which men accounted for $64.0 \%$, women $-36.0 \%$. In the examined patients with DPN, the (Homeostasis model assessment) HOMA index on average exceeded the normative indices by 2.2 times $(\mathrm{p}<0.01)$. There were no significant differences in the rates between men and women. Only the insulin content in the blood and the HOMA-IR value in men were higher by $52.2 \%$ $(\mathrm{p}<0.05)$ and by $36.6 \%(\mathrm{p}<0.05)$, respectively. The level of adiponectin in both men and women was significantly lower than the reference values, respectively 2.4 times $(p<0.01)$ and 1.3 times $(p<0.05)$. The increase in adiponectin in women was 1.5 times $(\mathrm{p}<0.05)$. The content of adiponectin in the blood in women correlated with the mean direct link to glycohemoglobin $(\mathrm{r}=+0.377)$, and in men the closest relationship of adiponectin with the insulin resistance index ( $\mathrm{r}=+0.421)$ was revealed. The expediency of using the results of the level of adiponectin in the pathogenesis of DPN was established. The level of adiponectin is an important criterion for determining the degree of severity, control of treatment, as well as for determining the prognosis of the disease.

Keywords: diabetic polyneuropathy, type 2 diabetes, insulin resistance, adiponectin, correlation.

Redaksiyaya daxil olub: 14.08 .2018

Çapa tövsiy olunub: 07.09.2018

Rayçi: prof. Mirzazadə V.A. 